\title{
Controlled Reproduction along with Crossbreeding for Genetic Up-gradation of Non-descriptive Goats
}

\author{
Shrikant Dodamani ${ }^{1}$, Naveen Kumar, G.S. ${ }^{1}$, Jayashree, R. ${ }^{1}$, Shivakumar, M.C. ${ }^{2}$, Sahadev ${ }^{3}$, \\ M.D. Suranagi ${ }^{1}$ and Karthikeyan, A. ${ }^{1}$ \\ ${ }^{1}$ Department of Animal Genetics \& Breeding, Veterinary College, KVAFSU-BIDAR, Bidar, INDIA \\ ${ }^{2}$ Department of Livestock Farm Complex, Veterinary College, KVAFSU, Bidar, INDIA \\ ${ }^{3}$ Department of Veterinary Gynaecology and Obstetrics, Veterinary College, KVAFSU, Bidar, INDIA \\ *Corresponding author: S Dodamani; E-mail: shri537@gmail.com
}

Received: 03 Oct., 2019

Revised: 31 Oct., 2019

Accepted: 15 Nov., 2019

\begin{abstract}
The present study was aimed on the genetic improvement of non-descriptive goats through estrus synchronization and by crossbreeding with Beetal goats they were reported to be a good milker, having higher body weight and dressing percentage. AVIKESIL-S, indigenously developed progesterone intra-vaginal sponges were utilized for estrus synchronization in does maintained at livestock farm complex, Veterinary College, Hassan. Response to estrus synchronization was noticed in all the does $(100 \%)$ under study, irrespective of the genetic background. Natural service was practised with three mating designs $i e$. G1-Beetal $\times$ Beetal, G2-Beetal $\times$ non-descriptive, G-3 non-descriptive $\times$ non-descriptive. Pregnancy test was performed with ultrasonography at 45 days post-mating. The conception rates in does of G1, G2 and G3 groups were 87.5, 87.5, and 75.0\% respectively. Kidding rate were $85.7,85.7$ and $100.0 \%$ in G1, G2 and G3 groups, respectively. Litter sizes were $1.5,1$ and 1 in G1, G2 and G3 groups, respectively. Average birth weight in G1, G2 and G3 groups were 3.82 $\pm 0.20,2.82 \pm 0.12$ and 2.00 \pm 0.09 $\mathrm{kg}$, respectively and average daily gain in G1, G2 and G3 groups were $42.86 \pm 1.69,33.81 \pm 1.28$, and $33.57 \pm 0.87 \mathrm{~g}$, respectively. Better growth performances were noticed up to 3 months of study period in G1 and G2 compared to G3 groups. It could be concluded that combined utilization of ES technology and crossbreeding in non-descriptive goats would provide superior kids for bulk marketing and ease management by avoiding dispersed kidding. Also more number of animals would be available for selection thus increasing the selection intensity their by improving the genetic improvement.
\end{abstract}

Keywords: Intra-vaginal sponges, Estrus synchronization, Crossbreeding, Non-descriptive Goats

Goats play an important role in the livelihood of a large proportion of landless as well as small and marginal farmers, where agricultural and dairy farming are not feasible. Goat contributes about 26.40 per cent of the total livestock population and shares about 13.74 per cent and 4.00 per cent of nation total meat and milk production, respectively (BAHS, 2018). The availability of meat in India is only about $2.96 \mathrm{~kg} /$ year/person against the ICMR recommendation of $11 \mathrm{~kg} /$ year/person. With increase in human population and changing trends in food habits, the demand for meat is increasing, thereby posing a great challenge to meet the requirement. Thus it is apparent that there exists a huge gap need to be addressed in near future.
The population of Goat is 135.17 million with a change 7.79 per cent decline in male Goats (Livestock census, 2012). This decline in male population was attributed to more number of slaughtering of the male animals for meat purpose at younger age. This trend leads to increased demand for chevon in the country as compared to the available animal from the natural reproduction rate. Thus, affect directly on availability of the high genetic merit male goats for future breeding purposes. The long term consequence of this could be shortage of high genetics

How to cite this article: Dodamani, S., Kumar, N., Jayashree, R. Shivakumar, M.C., Sahadev, Suranagi, M.D. and Karthikeyan, A. (2019) Controlled reproduction along with crossbreeding for genetic upgradation of non-descriptive goats. J. Anim. Res., 9(6): 903-906. 
merit bucks for mating purpose for future stock production. There is need to improve, rather than merely increasing the animal numbers of low yields. Currently, India has 34 registered breeds of Goat, out of which high genetic merit (more meat/milk per animal) indigenous registered breeds there exist only 12 registered breeds. These 12 breeds of high genetic merit Goat composite only of $33.7 \%$ of total Goat population, whereas the non-descriptive goats forms total of $61.26 \%$ of total population (Breed Survey Book, 2013), showing the huge potential to improve the meat production and also per unit holding of goats by a farmer. Hence to increase the meat and milk production per animal, emphasis has to be given on genetic improvement of existing non-descriptive Goats through up gradation with high genetic merit animals amongst suitable indigenous registered breeds. As per National Action Plan (NAP) on Goats, identified three key areas for doubling the income of goat farmers ie Improvement in per animal productivity, Increase in production intensity and efficient utilization of cost of production (NAP on Goats, 2017). Hormonesynchronized breeding and mating with high genetic merit buck of registered breed could be a solution for achieving the key areas suggested by NAP on Goats. Hence the aim of present research was to demonstrate synchronized breeding in non-descriptive goats for planned kidding and crossing those synchronized non-descriptive does with high genetic merit Beetal buck to improve both meat and milk production performance in non-descriptive goats.

\section{MATERIALS AND METHODS}

\section{Location}

The experiment was conducted just before the onset of breeding season. Experiment was conducted in Livestock farm complex (LFC), Veterinary College, Hassan, Karnataka, which is located at $76^{\circ} 6^{\prime} \mathrm{E}$ longitude, $13^{\circ} 0^{\prime} \mathrm{N}$ latitude and Altitude is 250-300 meters from mean sea level in major areas, 300-500 meters in some areas and 150-250 meters in remaining areas. Average annual rainfall ranged from 611 to $1054 \mathrm{~mm}$. Soils is red sandy loam in major area and red loam in remaining area. Climatic extremity in terms of ambient temperature, relative humidity ranges from $15^{\circ}$ to $32{ }^{\circ} \mathrm{C}$ and 2 to $91 \%$, respectively.

\section{Source of experimental animal}

Experimental animals were selected from the LFC,
Veterinary College, Hassan, Karnataka. All animals under the experiments were apparently healthy and were kept under similar managemental regimes. Animals were prevented from grazing to avoid accidental mating and were maintained under stall feeding throughout the experimental period. All animals were treated with deworming agent to avoid internal parasitism.

\section{Estrus Synchronization protocol}

Total of twenty four sexually matured does which were under normal oestrus cycle were selected after screening the animals using ultrasonography for non-pregnancy. Out of which eight does were Beetal and rest sixteen were non-descriptive belonging to two different genetic groups. Estrus Synchronization (ES) was achieved using indigenously developed intra-vaginal sponges obtained from CSWRI, Avikanagar. All does under study were subjected to $350 \mathrm{mg}$ progesterone impregnated intravaginal sponges, which were retained for 12 days followed by administration of 200 I.U. PMSG (Folligon, Intervet, Holland) intramuscularly for each doe immediately after sponge withdrawal.

\section{Mating design}

Natural service was practised after detecting estrus signs in does following ES treatment. Three mating designs were used ie. G1-Beetal $\times$ Beetal, G2-Beetal $\times$ non-descriptive, G-3 non-descriptive $x$ non-descriptive. Eight Beetal and eight non-descriptive does were put to cross with two Beetal bucks and rest eight non-descriptive does were crossed with two non-descriptive bucks. Does after natural mating were prevented from grazing and reared under similar managemental regime and were monitored for the presence of vulva discharge along with ultrasonography screening at 45 days post mating for the confirmation of conception. Does were fed with $150 \mathrm{~g}$ of concentrate feed along with ad-libitum green fodder and water. Thus produced kids were recorded for their litter size at birth, birth weight and their body weight (BW) were recorded at an interval of every month up to three months of age and average daily weight gain were recorded. Kids born were all maintained under similar feeding and managemental regime in view to nullify the external factors affecting growth performance of the kids apart from internal factors. 


\section{Data and statistical analysis}

The data were subjected to analysis of variance with the genetic group as the factor and Duncan's multiple range test (Snedecor and Cochran, 1994). All statistical analysis were done using SPSS version 21.

\section{RESULTS AND DISCUSSION}

All the does (100\%) under experimental study exhibited estrus signs for intra-vaginal progesterone impregnated sponge treatment followed by PMSG injection at the time of withdrawal. De et al. (2015) experimented on 471 ewes of farmers herd for estrus synchronization using AVIKESIL-S intra-vaginal sponges and recorded around $79.4 \%$ estrus response. In this study eight Beetal does were in anestrus since one year and the farmer decided to cull them. All eight Beetal does (100\%) showed estrus signs within $24 \mathrm{hrs}$ of sponge withdrawl. Saha et al. (2018) used same treatment protocols in acyclic ewes with success rate of $88.20 \%$. Non-descriptive does (100\%) exhibited estrus signs only after $48 \mathrm{hrs}$ of the sponge withdrawal along with PMSG injection. These results were in accordance with Hashemi and Safdarian (2017) who compared different methods of estrus synchronization methods in does and reported that majority of the does under progesterone sponge plus PMSG treatment exhibits estrus signs within $48 \mathrm{hrs}$ of treatment withdrawal. The data on ES response, Pregnancy rate, kidding rate and litter size were depicted in Table 1. The litter size of 1.5 in Beetal does with 50\% of twinning, while the non-descriptive does had litter size of one without twinning.

Beetal is a heavy breed of goat with regular twinning ability (52.6\%) and attain about $21.83 \mathrm{~kg}$ body weights at 12 months of age (Thiruvenkadan, 2014). As per "Genetic Improvement of Sheep and Goat" (GISG) under National
Livestock Mission (2017) report, Beetal was found to be best suited for improving both meat and milk production with average male body weight of $59.07 \mathrm{~kg}$ and dressing percentage of $49.68 \%$ highest among the registered Goat breeds of India with average daily milk yield of 1.16 (in $\mathrm{kg})$.

Table 1: Pregnancy rate, Kidding rate, Litter size among groups under study

\begin{tabular}{ccccc}
\hline $\begin{array}{c}\text { Genetic } \\
\text { Group }\end{array}$ & $\begin{array}{c}\text { Success rate } \\
\text { of ES }\end{array}$ & $\begin{array}{c}\text { Pregnancy } \\
\text { rate }\end{array}$ & $\begin{array}{c}\text { Kidding } \\
\text { rate }\end{array}$ & Litter size \\
\hline Group1 & $100(8 / 8)$ & $87.5(7 / 8)$ & $85.7(6 / 7)$ & $1.5(9 / 6)$ \\
Group 2 & $100(8 / 8)$ & $87.5(7 / 8)$ & $85.7(6 / 7)$ & $1.0(6 / 6)$ \\
Group 3 & $100(8 / 8)$ & $75(6 / 8)$ & $100(6 / 6)$ & $1.0(6 / 6)$ \\
\hline Total & $\mathbf{1 0 0 ( 2 4 / 2 4 )}$ & $\mathbf{8 3 . 3 ( 2 0 / 2 4 )}$ & $\mathbf{9 0 . 0 ( 1 8 / 2 0 )}$ & $\mathbf{1 . 1 6 ( 2 1 / 1 8 )}$ \\
\hline
\end{tabular}

These recommended characteristics of Beetal made it preferring for up-gradation of non-descriptive goats thereby creating a better economic returns to the livestock keepers. The mean and standard error for data on birth weight, body weight at $1^{\text {st }}$ month, body weight at $2^{\text {nd }}$ month, body weight at $3^{\text {rd }}$ month and average daily gain among kids of three genetic groups were given under the table 2 .

Mean birth weight of Beetal kids was $3.82 \pm 0.20 \mathrm{~kg}$, while it was $2.82 \pm 0.12$ and $2.00 \pm 0.09 \mathrm{~kg}$ for Beetal crossbred and non-descriptive kids, respectively. Birth weight in Beetal and its crossbred kids were significantly $(\mathrm{P} \leq 0.01)$ higher than their contemporary non-descriptive kids born in similar time period. Similar kind of fashion was noticed for body weight at $1^{\text {st }}$ month, $2^{\text {nd }}$ month and $3^{\text {rd }}$ month of age among three genetic groups under study. Present study findings were in concordance with Mallick et al. (2017), who reported birth weight of local goats kids was $1.56 \pm 1.23$ $\mathrm{kg}$ and while Beetal $\times$ local cross kids was $2.44 \pm 0.04 \mathrm{~kg}$.

Table 2: Mean \pm SE values of Birth weight, BW at 28D, BW at 56D, BW at $84 \mathrm{D}$ and ADG among three genetic groups

\begin{tabular}{|c|c|c|c|c|c|}
\hline Genetic Group & $\begin{array}{l}\text { Birth weight } \\
\text { (in kg) }\end{array}$ & $\begin{array}{c}\text { BW at } 1^{\text {st }} \text { month } \\
\text { (in } \mathrm{kg} \text { ) }\end{array}$ & $\begin{array}{c}\text { BW at } 2^{\text {nd }} \text { month } \\
\text { (in kg) }\end{array}$ & $\begin{array}{c}\text { BW at } 3^{\text {rd }} \text { month } \\
\text { (in } \mathrm{kg} \text { ) }\end{array}$ & $\begin{array}{l}\text { ADG } \\
\text { (in g) }\end{array}$ \\
\hline Group1 & $3.82 \pm 0.20^{\mathrm{a}}$ & $4.98 \pm 0.21^{\mathrm{a}}$ & $6.04 \pm 0.15^{\mathrm{a}}$ & $7.42 \pm 0.11^{\mathrm{a}}$ & $42.86 \pm 1.69^{\mathrm{a}}$ \\
\hline Group 2 & $2.82 \pm 0.12^{b}$ & $3.58 \pm 0.12^{b}$ & $4.46 \pm 0.07^{\mathrm{b}}$ & $5.66 \pm 0.07^{b}$ & $33.81 \pm 1.28^{b}$ \\
\hline Group 3 & $2.00 \pm 0.09^{c}$ & $3.00 \pm 0.09^{c}$ & $3.86 \pm 0.12^{\mathrm{c}}$ & $4.82 \pm 0.15^{\mathrm{c}}$ & $33.57 \pm 0.87^{b}$ \\
\hline Total & $2.88 \pm 0.21$ & $3.85 \pm 0.24$ & $4.79 \pm 0.25$ & $5.97 \pm 0.30$ & $36.75 \pm 1.35$ \\
\hline
\end{tabular}

* The values in the column having different superscripts differ significantly at $\mathrm{p} \leq 0.01$. 
Also reported significant $(\mathrm{p}<0.05)$ difference among local and Beetal $\times$ local cross kids for body weight at 3 months of age group. The variation in preset results for growth performance in Beetal crossbred might be due to involvement of genotype and environmental factors. For average daily weight gain among kids belonging to three genetic groups showed different pattern, with Beetal kids showing significant $(\mathrm{P} \leq 0.01)$ average daily gain than its crossbred kids and non-descriptive kids under study. There was no significant difference among the crossbred kids and non-descriptive kids for average daily weight gain. These results indicate that the higher body weight of Beetal breed could be used to produce crossbred kids of higher birth weight in comparison to kids of nondescriptive goats in region of Hassan district of Karnataka. Additionally treating acyclic does by utilizing assisted reproductive technique like estrus synchronization would enhance the production potential of the herd. Thus by improving non-descriptive goats using high genetic merit goats increases animal productivity and herd productivity to fetch higher economic returns to the farmers.

\section{CONCLUSION}

Estrus synchronization with indigenously developed AVIKESIL-S progesterone impregnated intra-vaginal sponges and PMSG could be effectively used in nondescriptive does and crossing them with high genetic merit Beetal bucks to produce kids of heavier size from non-descriptive goats would reflect directly on the farmer economic returns.

\section{ACKNOWLEDGEMENTS}

Authors are thankful to SCSP/TSP, Government of Karnataka for providing budget and Karnataka Veterinary, Animal and Fisheries Sciences University for providing all facilities for conducting the present study.

\section{REFERENCES}

$19^{\text {th }}$ Livestock Census. 2012. All India report. Department of Animal Husbandry, Dairying and Fisheries, Ministry of Agriculture and Farmers welfare, GoI, New Delhi.
Basic Animal Husbandry \& Fisheries Statistics. 2018. All India report. Animal Husbandry Statistics Division, Department of Animal Husbandry, Dairying and Fisheries, Ministry of Agriculture and Farmers welfare, GoI, New Delhi.

De, K., Kumar, D., Sethi, D., Gulyani, R., and Naqvi, S.M. K. 2015. Estrus synchronization and fixed-time artificial insemination in sheep under field conditions of a semi-arid tropical region. Trop. Anim. Health Prod., 47(2): 469-472.

Estimated Livestock population breed wise based on breed survey. 2013. All India report. Department of Animal Husbandry, Dairying and Fisheries, Ministry of Agriculture and Farmers welfare, GoI, New Delhi.

Hashemi, M. and Safdarian, M. 2017. Efficiency of different methods of estrus synchronization followed by fixed time artificial insemination in Persian downy does. Anim. Reprod., 14(2): 413-417.

Innovative project for "Genetic Improvement of Sheep and Goat" (GISG) under National Livestock Mission. 2017. All India report. Department of Animal Husbandry, Dairying and Fisheries, Ministry of Agriculture and Farmers welfare, GoI, New Delhi.

Mallick, P.K., Prasad, S.M., Pourouchottamane, R. and Mohanta, R.K. 2017. Comparative Performance of Non-Descript Goats and their Crossbreds with Beetal: A Field Study. Indian Vet. J., 94(03): 71-73.

National Action Plan on Goats. 2017. All India report. Department of Animal Husbandry, Dairying and Fisheries, Ministry of Agriculture and Farmers welfare, GoI, New Delhi.

Saha, S., Kumar, D. and Naqvi, S. M. K. 2018. Estrus Induction and Artificial Insemination in Acyclic Ewes under Field Conditions of Semi-Arid Region of Rajasthan. Int. J. Livest. Res., 8(9): 248-254.

Snedecor, G.W. and Cochran, W.G. 1994. Statistical Methods. $8^{\text {th }}$ ed. Oxford and I.B.H. Publishing Company Pvt. Ltd., New Delhi.

Thiruvenkadan, A.K. 2014. Country reports: India, In: Asian Australasian Dairy Goat Network Country Reports 2013/14. Institute of Tropical Agriculture, University Putra Malaysia, UPM Serdang, Malaysia, pp. 19-32. 